\title{
Performance evaluation of rotary and flail shredders
}

\section{N. Sridhar and A. Surendrakumar}

See end of the Paper for authors' affiliation

Correspondence to :

\section{N. Sridhar}

Department of Farm

Machinery and Power, Agricultural Engineering College and Research Institute (T.N.A.U.), Kumulur, Trichy (T.N.) India
-ABSTRACT : A large portion of crop residues burnt in farming fields due to non - availability of labour and high cost of residue removal. Burning of crop residues causes environmental pollution as well as increase the loss of plant nutrients. Therefore, appropriate management of crop residues assumes a great significance. Shredders are widely used for shredding the crop residues into small pieces and their performance study is an important factor for wide scale adoption. The field experiments were carried out to evaluate the performance of shredders and estimate the operational cost. The performance of shredders in terms of field efficiency, shredding efficiency was investigated with respect to change in forward speed of operation viz., 2, 3 an $5 \mathrm{~km} \mathrm{~h}^{-1}$ and blade types viz., straight blade and flail blade with selected shredders. The experimental results revealed that increasing shredding efficiency by decreasing in forward speed of operation from 5 to $2 \mathrm{~km} \mathrm{~h}^{-1}$ with optimum peripheral velocity of rotary and flail shredders.

- KEY WORDS : Shredding efficiency, Field efficiency, Forward speed of operation, Blade type

-HOW TO CITE THIS PAPER : Sridhar, N. and Surendrakumar, A. (2018). Performance evaluation of rotary and flail shredders. Internat. J. Agric. Engg., 11(1) : 23-29, DOI: 10.15740/HAS/IJAE/11.1/ 23-29. 